\title{
PEMBUATAN MODEL CUSTOMER RELATIONSHIP MANAGEMENT (CRM) DINAS KESEHATAN DIY MENGGUNAKAN METODE COBIT 4.1 DENGAN DOMAIN DELIVERY AND SUPPORT (DS)
}

\author{
Ali Tarmuji ${ }^{(1)}$, Ilham Nurfuadi ${ }^{(2)}$ \\ Program Studi Teknik Informatika \\ JIn. Prof. Dr. Soepomo, S.H. Janturan Yogyakarta \\ e-mail : ${ }^{(1)}$ alitarmuii@tif.uad.ac.id, ${ }^{(1)}$ salhamilham@ gmail.com
}

\begin{abstract}
Abstrak
Perkembangan sistem informasi kesehatan pada Dinas Kesehatan DIY pada dasarnya sudah dikembangkan pada periode-periode sebelumnya, termasuk dengan adanya DGS (Digital Government Services), namun pelayanannya belum dapat dimaksimalkan contoh pelayanan informasi pada website dinkes DIY, hal tersebut masih tidak sepenuhnya di ketahui oleh banyak masyarakat, sehingga kurangnya pengetahuan masyarakat tentang informasi terbaru yang berkaitan dengan kesehatan. tahapan dalam penelitian ini yaitu pencarian data dengan metode observasi, wawancara, dan studi pustaka, analisis kondisi saat ini, analisis SWOT, analisis data meliputi operational CRM, analytical CRM, collaborative CRM, dan tahapan pembuatan model CRM seperti perancangan strategi pengembangan layanan dan aplikasi, pembuatan arsitektur data, arsitektur aplikasi, arsitektur teknologi dan infrastruktur jaringan, dan pengujian model CRM menggunakan uji kelayakan yang ditujukan ke Dinas Kesehatan DIY serta uji kepuasan terhadap customer. Berdasarkan hasil analisis dihasilkan kerangka model CRM Dinkes DIY yang dapat memberikan kemudahan dalam berinteraksi dengan customer melalui layanan yang tersedia.
\end{abstract}

Keywords : Customer Relationship Management (CRM), Dinas Kesehatan DIY, Pelanggan.

\begin{abstract}
The development of health information systems at the Department of Health DIY basically already developed in earlier periods, including the presence of DGS (Digital Government Services), but the ministry has not been able to maximize sample information service on the website Department of Health DIY, it is still not fully known by many society, so the lack of public knowledge about the latest information related to health. stage in this research is the search data by observation, interview, and literature study, analysis of current conditions, SWOT analysis, data analysis includes operational CRM, analytical CRM, collaborative CRM, and the stages of modeling CRM such as the design of the development strategy of services and applications, manufacture of data architecture, application architecture, technology architecture and network infrastructure, and testing models of CRM use due diligence devoted to DIY Health Service and customer satisfaction to the test. Based on the analysis results generated CRM DHO DIY model framework that can provide ease in interacting with customers through the services available.
\end{abstract}

Keywords: Customer Relationship Management (CRM), DIY Health Service, Customer.

\section{PENDAHULUAN}

Pemerintah memanfaatkan teknologi informasi untuk memberikan informasi yang up to date kepada masyarakat, sehingga harus ada media yang dapat menyalurkan informasi tersebut kepada masyarakat. Sejauh ini masyarakat menuntut adanya keterbukaan/transparansi dan keberpihakkan terhadap rakyat, khususnya menyangkut program pembangunan yang diselenggarakan oleh pemerintah. Berbagai upaya yang dilakukan oleh pemerintah untuk mendukung keterlibatan publik dalam program dan pelaksanaan pembangunan, yang salah 
satunya adalah fasilitasi informasi publik melalui website. Hal ini sejalan dengan komitmen pemerintah terkait dengan pembangunan e-government, sebagaimana diwujudkan pada Instruksi presiden no. 3 tahun 2003 tentang Kebijakan dan Strategi Nasional Pengembangan e-Government : setiap pimpinan lembaga negara, kepala daerah diamanatkan untuk mengambil langkah-langkah yang diperlukan sesuai dengan tugas, fungsi dan kewenangannya guna terlaksananya pengembangan e-government secara nasional.

Perkembangan sistem informasi kesehatan pada Dinas Kesehatan DIY pada dasarnya sudah dikembangkan pada periode-periode sebelumnya, termasuk dengan adanya DGS (Digital Government Services), namun pelayanannya belum dapat dimaksimalkan pada layanan informasi kesehatan bagi masyarakat contoh pelayanan informasi pada website dinkes DIY, hal tersebut masih tidak sepenuhnya diketahui oleh banyak masyarakat, sehingga kurangnhya pengetahuan masyarakat tentang informasi terbaru yang berkaitan dengan kesehatan. Kurangnya perencanaan dalam pengembangan sistem informasi pada Dinas Kesehatan DIY menyebabkan sistem informasi dan teknologi informasi tidak digunakan secara maksimal sehingga tidak dapat mewujudkan visi dan misi dalam jangka panjang.

Berdasarkan latar belakang di atas maka akan dibuat sebuah pemodelan CRM yang nanntinya akan membantu meningkatkan pelayanan di Dinas Kesehatan DIY.

\section{LANDASAN TEORI}

\section{a. Customer Relationship Management}

Menurut Surendro (2009): CRM merupakan sebuah pendekatan baru dalam mengelola hubungan pelayanan kedinasan dengan customer sehingga dapat memaksimumkan komunikasi, meningkatkan pelayanan melalui pengelolaan berbagai kontak yang berbeda dengan customer.Kerangka komponen CRM terdiri dari :

1) Operational CRM

Pada area ini difokuskan pada alur bisnis dari proses bisnis yang berhubungan dengan pelayanan di Dinas Kesehatan DIY.

2) Analytical CRM

Dalam hal ini melibatkan pengambilan data kuisioner yang nantinya digunakan untuk membuat target pencapaian kematangan di Dinas Kesehatan DIY.

3) Collaborative CRM

Collaborative CRM membahas tentang interaksi antar Dinas Kesehatan dengan

\section{b. Proses Bisnis} kemungkinan jalur komunikasi ke customer.

Proses bisnis menurut Surendro (2009): adalah suatu kumpulan aktivitas atau pekerjaan yang saling terkait untuk menyelesaikan suatu masalah tertentu atau yang menghasilkan produk atau layanan.

\section{METODE PENELITIAN}

Tahapan pada penelitian ini dimulai dari melakukan pengamatan secara langsung dan tanya jawab dengan pegawai di Dinas Kesehatan mengenai kondisi saat ini yang meliputi proses bisnis, data, aplikasi yang digunakan, teknologi, dan sumber daya manusia. Secara lebih detail, adapun tahap-tahap dalam penyusunan penelitian meliputi:

a. Analisis kondisi saat ini

Tahapan pemodelan kondisi saat ini adalah tahap untuk mengetahui kondisi pelayanan yang sedang berjalan di Dinas Kesehatan.

b. Analisis SWOT

Merupakan tahap unutk mengidentifikasi berbagai faktor secara sistematika untuk merumuskan strategi Dinas Kesehatan.

c. Analisis data

Pada tahap analisis data dilakukan dengan melakukan analisis terhadap kondisi pelayanan saat ini dan terhadap strategi peekembangan di masa depan dengan menerapkan :

1) Operational CRM

Operational CRM membahas tentang proses bisnis yang berjalan ada Dinas

Kesehatan DIY. Proses bisnis lebih ditujukan kepada proses

yang berbasis pada pelayanan di bidang kesehatan. 
2) Analytical CRM

Analytical CRM membahas mengenai data, dalam hal ini proses pengambilan data, analisis data, dan penggunaan data.

3) Collaborative CRM

Collaborative CRM membahas jalur komunikasi yang dijadikan alat untuk melakukan interaksi dengan customer seperti website, chat, via telephon, fax, email.

d. Analisis kondisi yang diharapkan

Merupakan tahap untuk mengidentifikasi kondisi yang diharapkan Dnas Kesehatan DIY untuk masa depan.

e. Portofolio aplikasi

Portofolio disini yaitu berfungsi untuk melengkapi proses penentuan aplikasi yang berhubungan dengan fungsi-fungsi bisnis yang ada di dinkes DIY.

f. Pembuatan model CRM

Tahap ini akan membangun sebuah rekomendasi model Customer Relationship Management pada Dinas Kesehatan DIY dengan membuat arsitektur teknologi, arsitektur aplikasi, arsitektur data dan kerangka CRM yang akan membantu terlayaninya kebutuhan customer di bidang kesehatan.

\section{HASIL DAN PEMBAHASAN}

\section{a. Analisis Swot}

Analisis SWOT dipetakan dari hasil analisis kondisi saat ini Dinas Kesehatan DIY. Kekuatan dapat diidentifikasi dengan menentukan kekuatan apa saja yang ada di Dinkes yang digunakan untuk mempertahankan fungsi bisnis yang berjalan. Kelemahan diidentifikasi berdasarkan kelemahan apa saja yang dapat menghambat kinerja pelayanan di bidang kesehatan yang ada di Dinkes yang kemudian setelah teridentifikasi maka Dinkes akan memperbaiki agar menjadi lebih baik. Dengan mengetahui peluang yang ada baik untuk kondisi saat ini maupun kondisi akan datang, Dinkes bisa lebih mempersiapkan diri untuk dapat mencapai peluang tersebut. Untuk mewujudkan peluang maupun mempertahankan kinerja pelayanan serta fungsi bisnis agar tetap stabil tentunya mengalami banyak ancaman. Ancaman dapat di minimalisirkan dengan mengidentifikasi ancaman apa saja yang akan dihadapi Dinkes untuk saat ini maupun akan datang.

\section{b. Analisis Data}

1. Operational CRM

Operational CRM membahas tentang proses bisnis yang berjalan pada Dinas Kesehatan DIY mengenai pelayanan terhadap customer,diantaranya :

a) Proses bisnis pelayanan surat masuk.

b) Proses bisnis pelayanan surat keluar.

c) Proses bisnis pelayanan perijinan pendirian sarana dan tenaga kesehatan.

d) Proses bisnis melaksanakan surveilans.

e) Proses bisnis pengadaan sarana dan prasarana kantor.

f) Proses bisnis pendidikan dan latihan teknis penyehatan lingkungan.

g) Proses bisnis peminjaman ambulans.

h) Proses bisnis pelatihan keseshatan.

i) Proses bisnis penanganan keluhan melalui web dinkes.

j) Proses bisnis pengelolaan website.

k) Proses bisnis permohonan surat jaminan kesehatan.

l) Proses bisnis koordinasi dinas Kab/Kota dengan DIY.

m) Proses bisnis pengolahan data STP.

n) Proses bisnis pendaftaran pasien rawat jalan.

o) Proses bisnis permohonan penyerahan tenaga kesehatan.

2. Analitycal CRM

Analytical CRM membahas mengenai data, dalam hal ini proses pengambilan data, analisis data menggunakan kuisoner I Control Diagnotics untuk menentukan proses dalam mencapai tujuan TIK dan Kuisoner II Maturity Level. Kuisioner Delivery and Support atau DS yang diambil hanya berorientasi pada pelayanan saja, sehingga menghasilkan kuisioner DS yang berorientasi pada pelayanan yaitu DS2 mengenai mengelola layanan pihak eksternal, DS 3 mengenai mengelola kinerja dan kekuatan TIK, DS 4 mengenai memastikan pelayanan yang berkelanjutan, DS 5 mengenai 
memastikan keamanan sistem, DS 8 mengenai mengelola insiden dan kerusakan, DS 11 mengenai mengelola data, DS 12 mengenai mengelola alat-alat/kebutuhan fisik, DS 13 mengenai mengelola operasional TIK. Hasil analisis data akan digunakan untuk acuan dalam mencapai kondisi palayanan yang diharapkan agar sesuai dengan visi, misi, tujuan, dan sasaran Dinas Kesehatan.

3. Collaborative CRM

Dilihat dari Organization Relationship terdiri dari Dinkes dengan masyarakat, Dinkes dengan Dinkes Kab./Kota, Dinkes dengan BAPEDA, Dinkes dengan Rumah Sakit, Dinkes dengan Biro Organisasi, Dinkes dengan DPPKA, Dinkes dengan perguruan tinggi.

\section{c. Pembuatan model CRM}

Pembuatan model CRM di Dinkes meliputi pembuatan arsitektur data, arsitektur aplikasi, arsitektur teknologi dan kerangka model CRM.

\section{Arsitektur Data}

Arsitektur data diidentifikasi berdasarkan kebutuhan data dari masing-masing proses bisnis yang ada di Dinkes. Penggambaran arsitektur data dilakukan dengan menggunakan Entity Relationship Diagram (ERD) seperti pada Gambar 1.

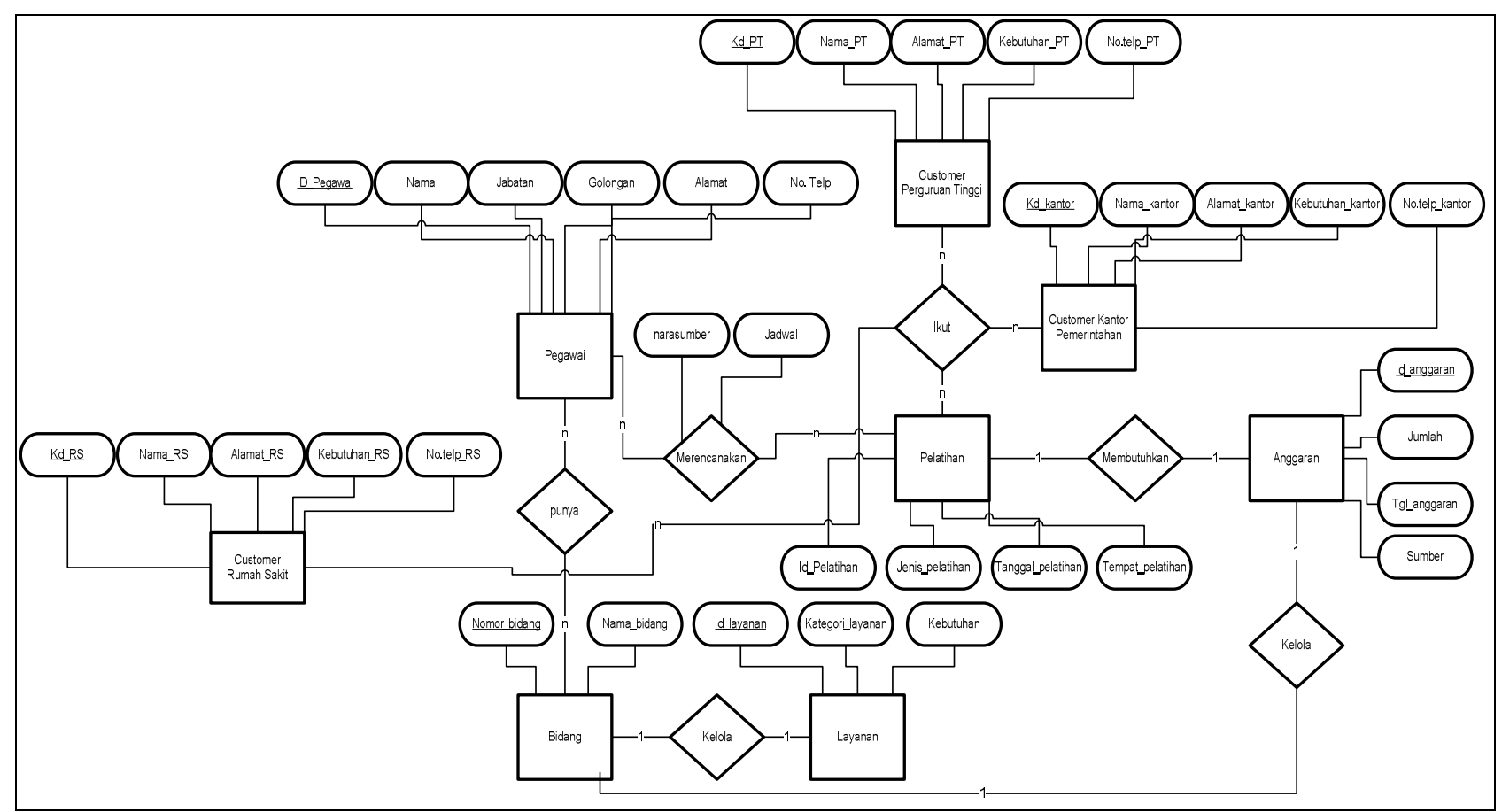

Gambar 1. ERD Dinas Kesehatan DIY

Pada gambar 1, menjelaskan tentang hubungan setiap entitas di Dinkes serta relasi yang dilakukan. Entitas-entitas yang direlasikan memiliki kardinalitas yang terdiri dari 3 macam yaitu 1:1 (one to one)/satu ke satu, $1: \mathrm{n}$ (one to many)/satu kebanyak, n:n (many to many)/banyak ke banyak. Entitas-entitas yang direlasikan dapat dijelaskan dalam tabel 1 berikut ini : 
Tabel 1. Entitas data pada Dinas Kesehatan DIY

\begin{tabular}{|c|c|c|}
\hline $\begin{array}{l}\text { Nama Entitas } \\
\text { Deskripsi } \\
\text { Atribut }\end{array}$ & & $\begin{array}{l}\text { Pegawai } \\
\text { Orang yang bekerja di dinas } \\
- \text { ID Pegawai } \\
- \text { Nama_pegawai } \\
- \text { Jabatan } \\
- \text { Golongan } \\
- \text { Alamat } \\
- \text { No. Telp }\end{array}$ \\
\hline $\begin{array}{l}\text { Nama Entitas } \\
\text { Deskripsi } \\
\text { Atribut }\end{array}$ & $\begin{array}{l}: \\
: \\
:\end{array}$ & $\begin{array}{l}\text { Rumah Sakit } \\
\text { Data rumah sakit baik itu pengadaan infrastruktur, perijinan, } \\
\text { pengaduan } \\
- \text { Kd. RS } \\
- \text { Nama_RS } \\
- \text { Alamat_RS } \\
- \text { Kebutuhan_RS } \\
- \text { No.telp_RS }\end{array}$ \\
\hline $\begin{array}{l}\text { Nama Entitas } \\
\text { Deskripsi } \\
\text { Atribut }\end{array}$ & $\begin{array}{l} \\
: \\
\text { e }\end{array}$ & 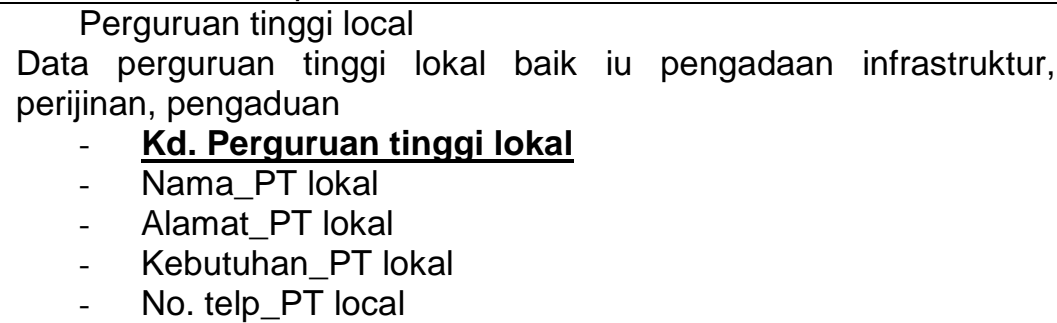 \\
\hline $\begin{array}{l}\text { Nama Entitas } \\
\text { Deskripsi } \\
\text { Atribut }\end{array}$ & $\begin{array}{l}: \\
:\end{array}$ & $\begin{array}{l}\text { Kantor Pemerintahan } \\
\text { Data pemerintahan baik itu pengadaan infrastruktur, perijinan, } \\
\text { pengaduan } \\
- \text { Kd. kantor } \\
- \text { Nama_kantor } \\
-\quad \text { Alamat_kantor } \\
-\quad \text { Kebutuhan_kantor } \\
-\quad \text { No. telp_kantor }\end{array}$ \\
\hline $\begin{array}{l}\text { Nama Entitas } \\
\text { Deskripsi } \\
\text { Atribut }\end{array}$ & $\begin{array}{l}: \\
:\end{array}$ & $\begin{array}{l}\text { Keluhan } \\
\text { Ungkapan ketidakpuasan yang berupa kritikan } \\
-\quad \text { Nomor keluhan } \\
-\quad \text { Jenis keluhan }\end{array}$ \\
\hline $\begin{array}{l}\text { Nama Entitas } \\
\text { Deskripsi } \\
\text { Atribut }\end{array}$ & $\begin{array}{l}: \\
:\end{array}$ & $\begin{array}{l}\text { Pelatihan } \\
\text { Kegiatan untuk meningkatkan kualitas dan kuantitas peserta } \\
-\quad \text { ID pelatihan } \\
-\quad \text { Jenis pelatihan } \\
-\quad \text { Tanggal pelatihan } \\
-\quad \text { Tempat }\end{array}$ \\
\hline $\begin{array}{l}\text { Nama Entitas } \\
\text { Deskripsi } \\
\text { Atribut }\end{array}$ & $\begin{array}{l}: \\
:\end{array}$ & $\begin{array}{l}\text { Peserta } \\
\text { Orang yang melakukan kegiatan pelatihan } \\
-\quad \text { Nomor peserta } \\
-\quad \text { Nama } \\
-\quad \text { Alamat } \\
-\quad \text { No. telp }\end{array}$ \\
\hline $\begin{array}{l}\text { Nama Entitas } \\
\text { Deskripsi } \\
\text { Atribut }\end{array}$ & $\begin{array}{l}\vdots \\
\vdots \\
\vdots\end{array}$ & $\begin{array}{l}\text { Narasumber } \\
\text { Orang yang memberikan pelatihan } \\
-\quad \text { ID Narasumber } \\
-\quad \text { Nama } \\
-\quad \text { Alamat } \\
-\quad \text { Riwayat pendidikan } \\
-\quad \text { No. telp }\end{array}$ \\
\hline
\end{tabular}




\begin{tabular}{|c|c|c|}
\hline Nama Entitas & : & Surat \\
\hline $\begin{array}{l}\text { Deskripsi } \\
\text { Atribut }\end{array}$ & : & $\begin{array}{l}\text { Surat- surat yang masuk dan keluar di Dinas } \\
-\quad \text { Nomor surat } \\
-\quad \text { Tgl surat } \\
-\quad \text { Perihal } \\
-\quad \text { Alamat surat } \\
\end{array}$ \\
\hline Nama Entitas & : & Bidang \\
\hline $\begin{array}{l}\text { Deskripsi } \\
\text { Atribut }\end{array}$ & : & $\begin{array}{c}\text { Bagian di dinas yang mempunyai fungsi dan tugas masing-masing } \\
-\quad \text { Nomor bidang } \\
-\quad \text { Nama_bidang }\end{array}$ \\
\hline $\begin{array}{l}\text { Nama Entitas } \\
\text { Deskripsi } \\
\text { Atribut }\end{array}$ & $\begin{array}{l}\vdots \\
\vdots\end{array}$ & $\begin{array}{l}\text { Anggaran } \\
\text { Dana yang dikeluarkan untuk pelatihan } \\
-\quad \text { ID anggaran } \\
-\quad \text { Jumlah } \\
-\quad \text { Tanggal_anggaran } \\
\text { - } \quad \text { Sumber }\end{array}$ \\
\hline
\end{tabular}

\section{Arsitektur Aplikasi Pada Dinkes DIY}

Arsitektur aplikasi diindentifikasi berdasarkan fungsi-fungsi bisnis seperti yang terdefinisi dalam proses bisnis.

Tabel 2. Kandidat aplikasi pada Dinas Kesehatan DIY

\begin{tabular}{|c|c|c|c|c|}
\hline No. & $\begin{array}{c}\text { Kelompok } \\
\text { aplikasi }\end{array}$ & Kandidat aplikasi & $\begin{array}{l}\text { Fungsi } \\
\text { bisnis }\end{array}$ & Deskripsi \\
\hline 1. & $\begin{array}{l}\text { Sistem } \\
\text { informasi } \\
\text { kepegawaian }\end{array}$ & 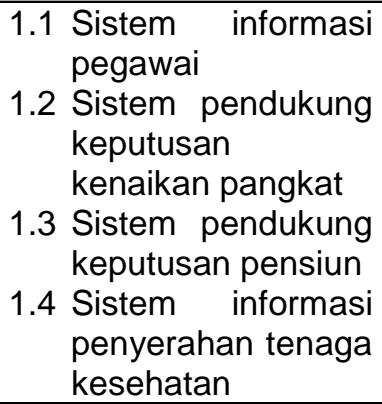 & \begin{tabular}{lr}
\multicolumn{2}{l}{ Proses bisnis kenaikan } \\
pangkat, pengusulan \\
pensiun, \\
penyerahan & denaga \\
kesehatan & dan \\
kepegawaian &
\end{tabular} & $\begin{array}{l}\text { Aplikasi ini } \\
\text { digunakan untuk } \\
\text { memberikan } \\
\text { informasi tentang } \\
\text { data pegawai, } \\
\text { pensiun, penetapan } \\
\text { kerja ataupun mutasi } \\
\text { serta dapat dijadikan } \\
\text { untuk penilaian } \\
\text { kinerja pegawai }\end{array}$ \\
\hline 2. & $\begin{array}{l}\text { Sistem } \\
\text { informasi } \\
\text { keuangan }\end{array}$ & $\begin{array}{l}\text { 2.1 Sistem informasi } \\
\text { penggajian } \\
\text { 2.2 Sistem informasi } \\
\text { pemasukan dan } \\
\text { pengeluaran dana } \\
\text { di Dinkes }\end{array}$ & $\begin{array}{lr}\text { Melakukan proses } \\
\text { bisnis penggajian dan } \\
\text { pemasukan dan } \\
\text { pengeluaran dana di } \\
\text { dinkes }\end{array}$ & $\begin{array}{l}\text { Aplikasi ini } \\
\text { digunakan untuk } \\
\text { melakukan } \\
\text { penggajian dan } \\
\text { untuk mengelola } \\
\text { pengeluaran serta } \\
\text { pemasukan di Dinas } \\
\text { agar keuangan } \\
\text { selalu terkontrol }\end{array}$ \\
\hline 3. & $\begin{array}{l}\text { Sistem } \\
\text { informasi } \\
\text { administrasi } \\
\text { data dan } \\
\text { pelaporan }\end{array}$ & $\begin{array}{l}\text { 3.1 } \text { Monitoring evaluasi } \\
\text { 3.2 Sistem informasi } \\
\text { jaringan data } \\
\text { 3.3 Sistem informasi } \\
\text { pengelolaan } \\
\text { sarana dan } \\
\text { prasarana } \\
\text { 3.4 Sistem informasi } \\
\text { surat dinas } \\
\text { 3.5 Sistem informasi } \\
\text { surveilains } \\
\text { kesehatan } \\
\text { 3.6 Sistem informasi } \\
\text { pengolahan STP }\end{array}$ & $\begin{array}{lr}\text { Proses } & \text { bisnis } \\
\text { penanganan surat } \\
\text { masuk, penanganan } \\
\text { surat keluar dan } \\
\text { laporan kinerja }\end{array}$ & 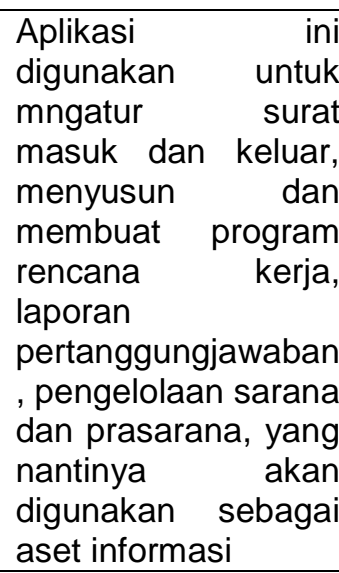 \\
\hline
\end{tabular}




\begin{tabular}{|c|c|c|c|c|}
\hline 4. & $\begin{array}{l}\text { Sistem } \\
\text { informasi } \\
\text { layanan } \\
\text { pelanggan }\end{array}$ & 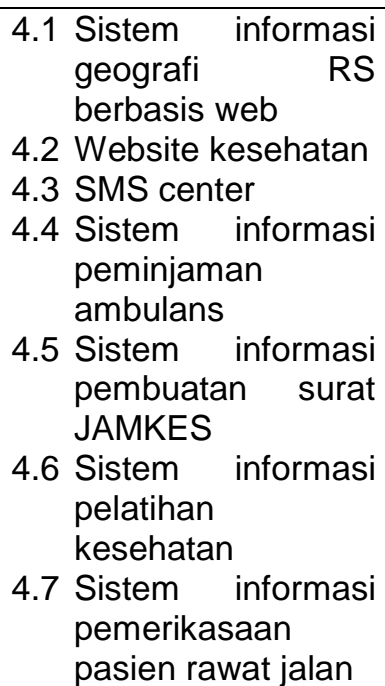 & $\begin{array}{lr}\text { Proses } & \text { bisnis } \\
\text { pembuatan } & \\
\text { permohonan } & \text { surat } \\
\text { JAMKES, peminjaman } \\
\text { ambulans, pelatihan } \\
\text { kesehatan, } \\
\begin{array}{l}\text { pemeriksaan } \\
\text { rawat jalan }\end{array}\end{array}$ & $\begin{array}{l}\text { Aplikasi ini lebih } \\
\text { diutamakan untuk } \\
\text { pelayanan } \\
\text { pelanggan baik itu } \\
\text { pegawai, } \\
\text { masyarakat, layanan } \\
\text { kesehatan, maupun } \\
\text { instansi/lembaga } \\
\text { terkait }\end{array}$ \\
\hline
\end{tabular}

\section{Arsitektur Teknologi Pada Dinas Kesehatan DIY}

Arsitektur teknologi digunakan unuk menggambarkan infrasruktur fisik perangkat keras dan jaringan yang mendukung sistem aplikasi yang digunakan untuk membangun CRM pada Dinkes, adapun jaringan konseptual Dinkes seperti pada Gambar 2.

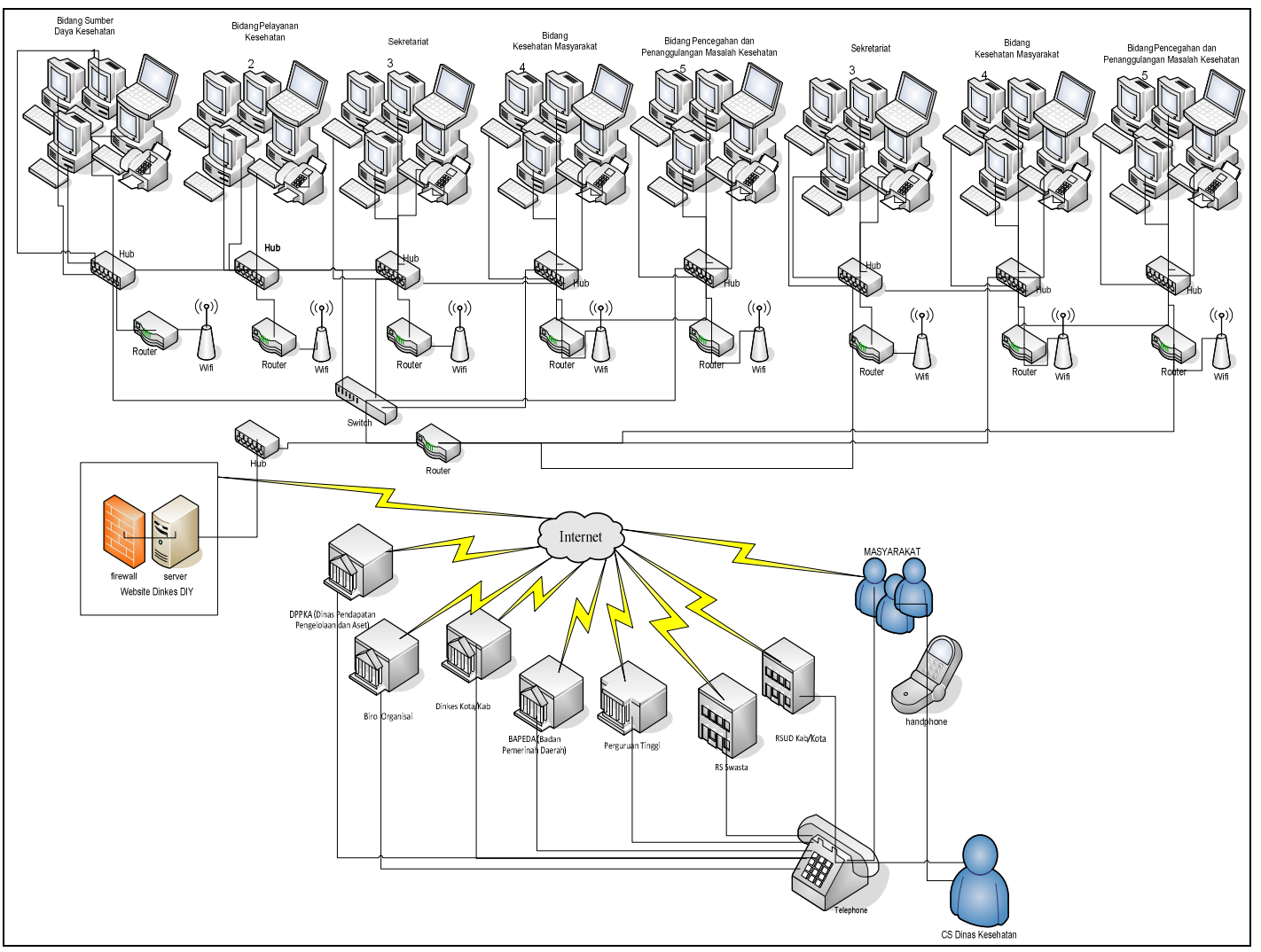

Gambar 2. Arsitektur jaringan Dinas Kesehatan DIY

Pada gambar 2, menjelaskan mengenai struktur jaringan pada Dinkes DIY dengan customer dinkes DIY. terhubung dengan fiber optic sebagai media transmisi kedalam jaringan internet. Dinkes terbagi menjadi 5 bidang dan 1 UPTD yang jarak setiap ruangan bidang berada pada lantai yang berbeda sehingga pemerataan jaringan menggunakan media wireless. 
4. Portofolio Aplikasi

Untuk melengkapi proses penentuan aplikasi yang berhubungan dengan fungsi-fungsi bisnis yang ada di dinkes DIY, serta kesesuaian antara strategi bisnis dan perencanaan strategi untuk sistem informasi yang terdiri dari aplikasi strategis, aplikasi operasional kunci, aplikasi potensi dan aplikasi pendukung.

\section{Kerangka Model CRM}

Pembuatan kerangka model CRM pada Dinkes digunakan untuk menggambarkan alur pelayanan yang dilayani oleh setiap bidang pada Dinkes dengan memanfaatkan sarana komunikasi dan SI yang dibangun. Kerangka model CRM pada Dinkes dapat dilihat pada Gambar 3.

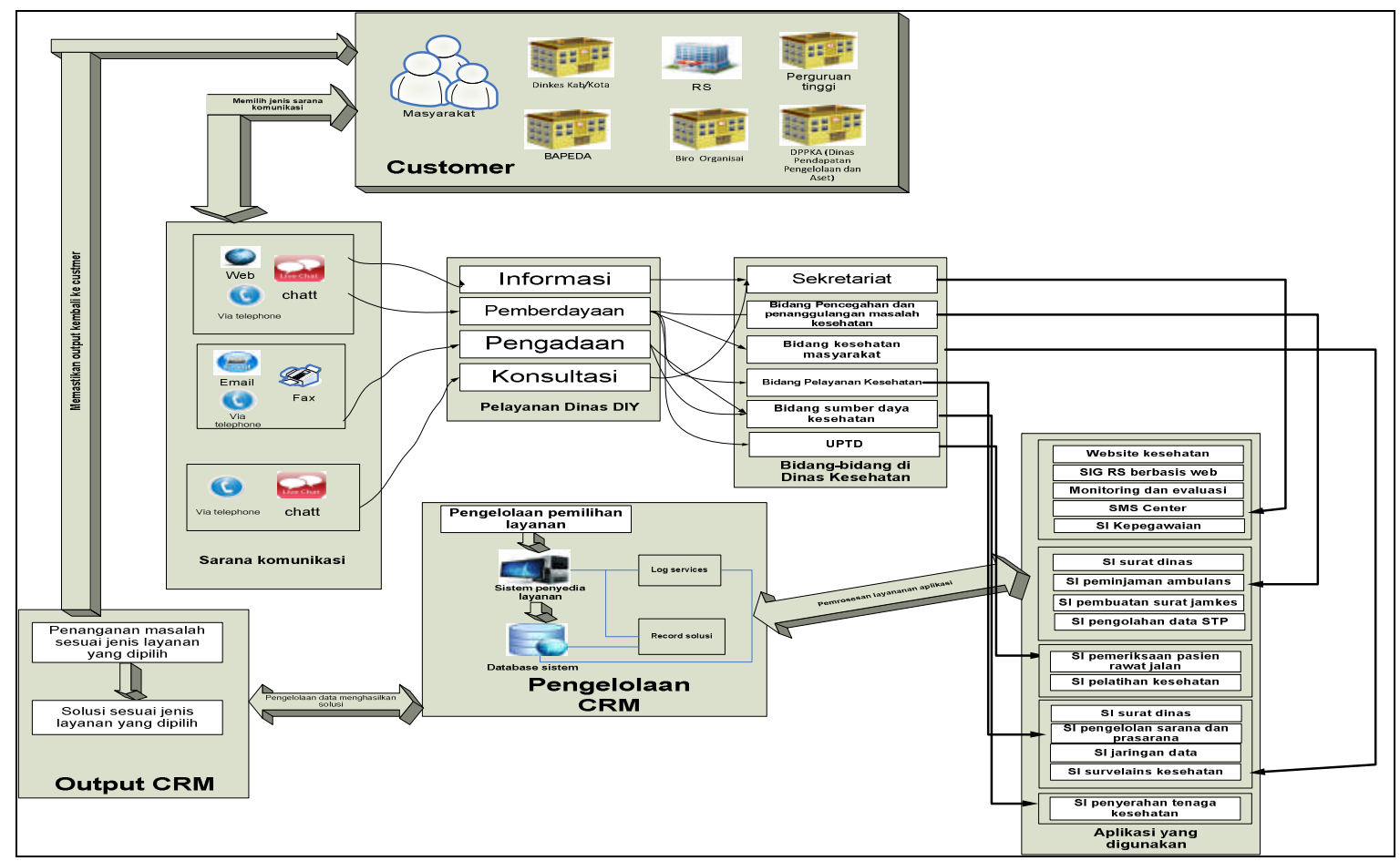

Gambar 3. Kerangka model CRM Dinas Kesehatan DIY

Pada Gambar 3 menjelaskan tentang bagaimana Dinkes melayani customer dengan menggunakan aplikasi yang ada dan berbeda setiap pelayanan tergantung dari kebutuhan customer.

\section{KESIMPULAN}

Hasil dari penelitian adalah sebuah model Customer Relationship Management (CRM) pada Dinas Kesehatan DIY yang dapat dijadikan acuan dalam mencapai tujuan dan sasaran Dinas Kesehatan DIY dalam hal pelayanan di bidang kesehatan kepada customer.

\section{DAFTAR PUSTAKA}

Oetomo, D., Sutejo, B., 2003, Pemodelan I-CRM Membina Relasi Dengan Pelanggan.com. Andi Offset, Yogyakarta.

Pemerintah DIY, 2010, Kerangka Acuan Pengembangan DGS Provinsi Daerah Istimewa Yogyakarta. Jogja Info Services, Yogyakarta.

Surendro, K., 2009, Pengembangan Rencana Induk Sistem. Informatika, Bandung.

Miftahul, M., Ade, 2011, Pembuatan Model Sistem Informasi Pada Dinas Kesehatan Provinsi DIY Berbasis SOA (Service Oriented Architecture). Universitas Ahmad Dahlan, Yogyakarta. 